\title{
Susan Carson in conversation with Donna Lee Brien on research higher degree examination administration
}

\author{
September 2013, Brisbane
}

\begin{abstract}
:
This paper is the edited transcript of a conversation between Susan Carson and Donna Lee Brien about an administrator's perspective of the process of examining doctoral theses in the creative industries. Susan was central to the process in the Faculty of Creative Industries from 2008 to 2012, and has overseen the carriage of examination for creative arts theses in the creative industries disciplines of creative writing, performance studies, media and communication, journalism, film and television, visual arts, and interaction and visual design.
\end{abstract}

Biographical notes:

Dr Susan Carson is a Senior Lecturer in Creative Writing and Literary Studies in the Creative Industries Faculty at QUT. Sue was awarded an OLT Citation for Outstanding Contributions to Student Learning in 2013; and she was a leader on the OLT 20122013 project Building distributed leadership for effective supervision of creative practice higher research degrees. Between 2008 and 2012 Sue was Head of Postgraduate Studies in the Creative Industries Faculty, with a particular focus on the development of practice-led projects in the Honours environment. Sue is widely published in Australian Studies and more recently has developed a research group in Cultural Tourism at QUT.

Professor Donna Lee Brien is Professor of Creative Industries, Assistant Dean (Postgraduate and Research), Creative and Performing Arts, and Chair of the Creative and Performing Arts Research Group for the Learning and Teaching Education Research Centre at Central Queensland University. A chief investigator on a new nationally funded project developing a MOOC on creativity for postgraduate coursework students, Donna has been a key project team member of three nationally funded learning and teaching projects - Examination of doctoral degrees in creative arts: process, practice and standards; CreateEd: strengthening learning and teaching leadership in the creative arts; and the Australian postgraduate writers network; and was awarded an ALTC Citation for Outstanding Contributions to Student Learning in 2006. Past President of the national peak body, the Australasian Association of Writing Programs, Donna is widely published, with over 120 refereed scholarly publications.

Keywords:

Examination - Creative arts - Policy - Procedures 
Dr Susan Carson is currently a supervisor and examiner of research higher degrees in the creative industries. She was the Head of Postgraduate Studies for the Creative Industries Faculty at QUT from 2008 to 2012. Donna and Sue, who worked together at QUT from 1998 to 2004, began by reflecting on both Sue's current role and her past experience of the examination process.

Donna: What is your current role in the examination process?

Sue: Principally, I now contribute to the process of examination as a final seminar panel member and chair of examination panels.

Donna: Do you think the examination process works effectively at present?

Sue: The most difficult aspect is finding suitable examiners. An open access bank of examiners would be wonderful. It would also be useful to have clarity nationally around administrative expectations of the practice-led examination process. I have found some potential examiners cannot complete the required paperwork in a timely way although they may have expert knowledge in the area.

Donna: Do you have any experience of the viva voce?

Sue: $\quad$ No.

Donna: I know you have had extensive experience in doctoral degree examination in the creative arts, including in the management of the examination process. Would you describe this?

Sue: My experience relates to doctoral degree examination in two ways: first as an examiner of creative arts projects since 2003; and second as the Head of Postgraduate Studies, Creative Industries Faculty, QUT, from 2008 until 2012. I examine practiceled projects in the creative arts in the context of my disciplinary background (Creative Writing and Literary Studies). These projects include Honours, Master of Arts Research, Doctorate of Creative Industries-a professional doctorate-and $\mathrm{PhD}$. As the Head of Postgraduate Studies, I chaired many Faculty panels for the PhD program in a number of different disciplines (from music to dance) and wrote the reports that guided candidates towards the successful completion of the examination process.

Donna: That last part - writing those reports - that is an interesting part of the process.

Sue: I think it is an activity that can be seen as a form of internal examination.

Donna: How so?

Sue: I feel that the reports can offer candidates a way forward, especially if their project has become inward-looking over time or if there has been a focus on certain areas at the expense of other questions. A well-structured report should clarify what the project will offer as new knowledge and offer guidance rather than exist as a summary account of proceedings. This report gives the candidate the opportunity to stand back and see their work through the eyes of others; and the report also provides support for the supervision team. Often a critical aspect of the project will emerge through the report writing process. The report can capture the examination panel's 
ideas and suggestions and help the supervision team and the candidate in a very practical way towards examination.

Donna: The academic management process of examination is certainly multifaceted.

Sue: Yes, you see the candidate become confident in their project over time as he or she moves through the process, which is rewarding, although the entire process is quite intricate. In relation to the academic management of the process, I signed off on all faculty higher research degree candidates' documents for submission for examination. I also often assisted supervisors with the selection of examiners. I was responsible for checking the nomination of examiner forms for any conflict of interest and monitored the process of examination until the reports were received. I assisted examiners who had queries about our examination process, especially in relation to practice-led research, although I found that most examiners were familiar with QUT expectations.

Donna: What did you spend the most time on?

Sue: Two key areas: the first involves negotiation between the candidate, discipline staff, supervisors and the university in the instance of a difficult candidature. These negotiations can demand fast responses, or they can be protracted. Second, at the point of the return of examiners' reports, especially when those reports ask for major changes. In such instances, I worked with the candidate and supervisor to make changes to the document to fulfill both examiner expectations as well as the candidate's desire for completion. The speed of response depended on the degree of the candidate's resistance to change. It was also dependent on the state of the supervisor-candidate relationship. Once the changes were made to my satisfaction, and all requirements of the cniversity-wide Research Degrees Committee were met, I would then, and only then, sign off on the project.

Donna: This would also have been multiplied by the fact that you have a number of different doctoral degrees in the creative arts?

Sue: We had/have the Doctorate of Creative Industries (DCI), a professional doctorate and the $\mathrm{PhD}$.

Donna: What, do you think, is the proportion of NTROs to traditional at QUT? And are they actually distinguished in the research office?

Sue: The proportions have shifted in the Creative Industries Faculty with the merger in 2011 with the School of Design. School of Design higher research degrees are less likely to be practice-led, so the previous 70/30 Faculty split in favour of practice-led has changed to $50 / 50$.

Donna: Does QUT consider the creative arts as different, similar or special?

Sue: In my opinion, it is considered as different, but not of lesser scholarly status. University level committees have been considering creative arts documents (via milestones) for more than five years and the diversity of project form, and the focus on practice, is accepted.

Donna: I am interested in your rules and procedures for Creative Arts doctorates and your perception of how effective and clear they are. 
Sue: The rules and procedures are publicly available, online, via the QUT Manual of Policies and Procedures.

The degree of 'Doctor of Philosophy' (PhD) at QUT signifies that the holder has undertaken a substantial piece of original research which has been conducted and reported under proper academic supervision and in a research environment for a prescribed period. The PhD's contribution to knowledge rests on the originality of the idea/approach and/or interpretation of findings and, in some cases, the discovery of new knowledge. The award of a PhD demonstrates that the candidate has the ability to communicate research findings effectively in the professional arena and in an international context.

'Examination' means the formal testing of the candidate's thesis while under examination to critically evaluate whether the conditions for the award of the Higher Degree Research have been met.

'Examiners' means the experts appointed to undertake examination of the candidate's thesis.

'Faculty' means the relevant faculty of QUT.

'Higher Degree Research' means any postgraduate masters or doctoral degree with a research component comprising 66.6 percent or more of the total course of study. Research Higher Degrees are also referred to as Higher Degrees Research or postgraduate research.

'Masters by research' means a Master's degree, which has a research component comprising 66.6 percent or more of the total course of study.

'Professional Doctorate (Research)' means a doctoral degree at QUT, which has a research component comprising 66.6 percent or more of the total course of study.

'Research' comprises information gathering and knowledge creation, analysis, critical investigation and communication in a fashion acceptable in the field of endeavour. Knowledge creation would encompass creative and professional practice and reflection on this practice.

'Thesis' means a document or collection of materials, which for thesis by creative works includes an exegesis. The thesis presents the candidate's research and findings and is presented for examination. In the award course the thesis component is deemed equivalent to the research component.

In general terms, the above are clear guidelines. The phrase 'which for thesis by creative works includes an exegesis' is quite short. However, the brevity is intended to give candidates multiple options within the 'creative works plus exegesis' model. I found that attempts (at the University level) to be more descriptive of the creative arts projects tended to have the reverse effect and close down certain options.

Donna: You mentioned that your policy and procedures are publicly available, online? Are these regularly updated, and if so, who by?

Sue: Yes, HDR policies are updated by the QUT Research Students Centre - as a 
draft for university approval.

Donna: Do you have separate guidelines for examiners of creative arts doctorates?

Susan: Yes, they are at https://wiki.qut.edu.au/display/pdpla/Thesis+Examination. This provides a mass of detailed information: guidelines, information and forms for candidates, supervisors, other staff and examiners.

Donna: Can you talk me through the examination process, from your point of view, from when the student advises they are ready to submit?

Sue: The decision re submission is usually made jointly between the principal and associate supervisors with the candidate. QUT expects candidates to submit within three months of presenting a final seminar (the date is dictated by their candidature timeline). Potential examiners might be contacted before the final seminar, or after, depending on whether the final seminar panel has asked for any changes to the project before submission. The principal supervisor approaches examiners informally, usually via email, and then fills in 'Nomination of examiner' form for the Research Students Centre's (RSC) higher degree research administration team. The examiner fills in the required forms and when they are returned, and the final documents are ready for submission at the supervisory level, the 'package' is sent to the RSC, which logs the submission and sends the material to the examiners. From that point, the RSC manages the examination process. The candidate can nominate to submit as an electronic attachment or in hard copy. A copy of the examination guidelines is sent to the examiner with the submission.

Donna: In your experience, are the examiners of creative doctorates different from examiners of more conventional doctorates?

Sue: The examiners can differ in relation to their experience of creative practice. In the past, certain projects might have been examined by a creative practitioner considered an 'expert' in an area. This person might have a substantial examination track record, and supervision record, but not a $\mathrm{PhD}$. This situation is diminishing, with most examiners now expected to have a doctorate. However, it is sometimes difficult to find doctorally-qualified examiners in some new areas of research. There are not many $\mathrm{PhDs}$ in the fashion discipline in Australia, for example.

In general, supervisors look for examiners who are practitioners, or have a demonstrable interest in creative practice (perhaps through their own research higher degree supervisions), or have a pertinent examination record, in conjunction with disciplinary or interdisciplinary scholarship. The examiner of creative doctorates is, therefore, different from examiners in other disciplines insofar as this examiner understands the creative journey and assesses the scholarly material in relation to that journey.

Donna: Did you read and consider all the examiners' reports?

Sue: As the Faculty HDR coordinator, I read all examiner reports. The reports are also read by the Research Student Centre administration staff. 
Donna: Do you think examiners actually read and follow the guidelines?

Sue: I believe there is evidence (in their reports) that the majority of examiners do read and follow the guidelines, but some do not. This lack of attention might be due to a number of reasons: the examiner is rushed, or the examiner knows the area very well and feels they do not need to write a fulsome report.

Donna: How do you deal with reports where examiners have clearly not followed the guidelines?

Sue: We would contact the examiner and explain the QUT process and if, at the end of the day, the examiner was unable to comply, the university would appoint another examiner. Fortunately, this is a very rare situation.

Donna: In terms of examiners' responses to the dissertations they are examining - do you think the system works - are reports fair commentary on the quality of work?

Sue: Generally yes. Most examiners, especially in the creative practice area, go to quite a lot of trouble to write an appropriate report and, in general. I have found the examination of the creative work very fair. I have found, moreover, that the tendency to write a very short report occurs more frequently in relation to a conventional thesis. In the creative practice area, candidates know that examiners are said to respond in more detail to the exegesis section of the project, but this knowledge does not seem to skew the candidates' own approach to their creative work. I understand, however, that a candidate's confidence in the validity of a creative arts doctoral program varies between institutions.

Donna: Do you have a sense of whether students and supervisors of Creative Art Doctorates want or expect the same sort of outcomes as in other fields?

Sue: If the students are interested in an academic track they want the same outcomes as other fields: post-graduate employment and the chance to work with their creative colleagues. If they are interested chiefly in pursuing their practice they may have different aims: Australia Council grants or other arts funding and they are more interested in being independent.

I think the supervisors in the creative practice areas often expect to mentor candidates into their respective creative areas post-completion. There is not, at this stage, a strong emphasis on joint publication as an outcome, either during or after the degree, which one finds in other fields. Creative practitioners have their creative outputs captured by ERA, but there is quite a lot of confusion as to who makes the decision about what work is captured and presented, and on what basis.

Donna: What are your principles when you're working on policy? Is it about making it more effective, or, about better outcomes?

Sue: I believe policy needs to provide a framework that is strong, yet supple, so that candidates have clarity but there is still the flexibility to engage with individual project circumstance. Policy should provide guidance, but this guidance should not constrict the project. If the creative question is rich and innovative, and the practice and research is thorough, then a better outcome will eventuate. 
Donna: From your perspective, what are your policies and procedures like in terms of their breadth, scope, rigour compared with comparative universities?

Sue: The broad frameworks are similar. I have found that one or two of the newer institutions with a focus on creative practice can have more layers of policies and procedures. However, this layering is directed at assuring national and international communities that the practice is at the highest level rather than being an instance of bureaucratic growth. There is increasing attention on asking a panel or group to review a project in the period between confirmation and the final seminar, a period when there are sometimes no milestones.

Donna: Are there any other comments you would like to make from your perspective about the examination of creative arts doctoral degrees?

Sue: I think that most examiners are keen to support creative arts programs and so produce a thorough report. Problems arise when there is a mismatch between the examiner's experience and the project aims. One of the problems of the 'newness' of the creative arts doctorate is finding examiners in particular fields. As well, it is often difficult to find information about the examination history of academic staff in some disciplines. On the plus side, the smaller 'community' of candidates and examiners means that there is less likelihood of the type of ethical problems I have noted in relation to examination in some of the traditional research areas.

Donna: That is very positive!

Sue: Yes, on reflection, it is. I think that there is an ever-increasing sophistication in relation to understanding creative practice as research (from both the practitioners and the academic managers) and the examiners have responded positively to such changes. 